\title{
Fabrication of $\mathrm{CNTs} / \mathrm{TiO}_{2}$ photoanodes for sensitive determination of organic compounds
}

\section{Q.1 Lihong Li, Min Yang, Shanqing Zhang ${ }^{1}$, Guiying Li, William Wen, Haimin Zhang and Huijun Zhao}

Environmental Futures Centre and Griffith School of Environment Gold Coast Campus, Griffith University, QLD 4222, Australia

E-mail: s.zhang@griffith.edu.au

Received 15 July 2010, in final form 11 October 2010

Published

Online at stacks.iop.org/Nano/21/000000

\begin{abstract}
Titanium dioxide $\left(\mathrm{TiO}_{2}\right)$ and carbon nanotubes $(\mathrm{CNTs})$ are the two most popular functional materials in recent years. In this study, $\mathrm{CNTs} / \mathrm{TiO}_{2}$ composite and $\mathrm{TiO}_{2}$ photoanodes were fabricated by a dip-coating technique, followed by subsequent calcination. The resultant photoanodes were characterized by scanning electron microscopy (SEM), x-ray diffraction (XRD), and UV-visible spectroscopy (UV-vis). The results suggest that the carbon nanotubes were successfully incorporated with the $\mathrm{TiO}_{2}$ nanoparticulates without damage and that the resultant $\mathrm{TiO}_{2}$ nanoparticles consisted of anatase and rutile. The $\mathrm{CNTs} / \mathrm{TiO}_{2}$ photoanodes were capable of oxidizing various types of organic compounds (e.g. glucose, potassium hydrogen phthalate, and phenol) in aqueous solutions in a photoelectrochemical bulk cell. In comparison with the pure $\mathrm{TiO}_{2}$ photoanode, the sensitivity of the photoanode for the detection of organic compounds has been improved by $64 \%$, while the background current was reduced by $80 \%$ due

Q.2 to the introduction of the CNTs. These advantages can be ascribed to the improved adsorptivity to organic compounds, increased absorption of UV light and enhanced electron transport at the $\mathrm{CNTs} / \mathrm{TiO}_{2}$ photoanode due to the introduction of the CNTs.
\end{abstract}

S. Online supplementary data available from stacks.iop.org/Nano/21/000000/mmedia

Q.3 (Some figures in this article are in colour only in the electronic version)

\author{
(Ed: Janet Thomas) \\ Ascii/Word/NAN/ \\ nano362824/PAP \\ Printed 29/10/2010 \\ Spelling US \\ Issue no \\ Total pages \\ First page \\ Last page \\ File name \\ Date req \\ Artnum \\ Cover date
}

\section{Introduction}

Up to now, titanium dioxide $\left(\mathrm{TiO}_{2}\right)$ has been a dominant photocatalyst owing to its non-toxic nature, superior photocorrosion resistance and excellent photocatalytic activity [1]. Various applications of nanostructured photocatalysts have been investigated, and the solar energy conversion and photocatalytic degradation of organic contaminants have been the main focuses [2-4]. Recently, the analytical applications of nanostructured $\mathrm{TiO}_{2}$ have been reported for environmental monitoring in the form of sensor arrays [5,6]. Nanostructured $\mathrm{TiO}_{2}$ films have been widely used as sensors for various gases, such as $\mathrm{H}_{2}$ [7], $\mathrm{O}_{2}$ [8], $\mathrm{CO}$ [9], methanol [10], alcohol vapor [11], humidity measurement [12] and also environmental

1 Author to whom any correspondence should be addressed. pollutants in wastewater [13]. Despite the great potential of these sensors, in order to expand the scope of the sensors toward a wide range of organic and inorganic contaminants, more advances in $\mathrm{TiO}_{2}$ nanostructured materials serving as sensors are much needed [5].

Carbon nanotubes $(\mathrm{CNTs}) / \mathrm{TiO}_{2}$ composite systems have attracted much attention in recent years due to the unique properties of CNTs. Taking advantage of the large surface area, extraordinary electrical conductivity, robust mechanical strength and thermal stability of CNTs, the $\mathrm{CNTs} / \mathrm{TiO}_{2}$ composite materials have been employed for a wide range of applications concerning energy and the environment [14], such as batteries [15], supercapacitors [16, 17], optoelectronics [18], electrocatalysis [19, 20], photocatalysis [21, 22] and sensing devices [23-27]. In the sensing applications, Llobet et al reported that the $\mathrm{CNTs} / \mathrm{TiO}_{2}$ hybrid film sensor was 
significantly more sensitive to oxygen than the pure $\mathrm{TiO}_{2}$ one. Moreover, the hybrid sensors could also be operated at a lower operating temperature $\left(350^{\circ} \mathrm{C}\right)$ than the pure $\mathrm{TiO}_{2}$ sensors $\left(500^{\circ} \mathrm{C}\right)$ [24]. Ueda et al developed the $\mathrm{CNTs} / \mathrm{TiO}_{2}$ hybrid gas sensor towards NO gas, which could be operated at room temperature and showed a good sensitivity [27]. The $\mathrm{CNTs} / \mathrm{TiO}_{2}$ composite materials have also been used in $\mathrm{NH}_{3}$ sensing [25], $\mathrm{H}_{2} \mathrm{O}_{2}$ sensing [23], and even biosensing for cancer cells [26].

In these applications, particularly in the sensing system and the photocatalytic degradation of pollutant in water treatment, the enhancements observed in the CNTs composite systems in comparison with the non-hybrid ones can be attributed to several possible merits contributed from CNTs: (i) higher adsorption capacity to reactant species due to the high surface area nature of the CNTs [28, 29]; (ii) photoexcitation under longer wavelength light [28, 29]; (iii) the relatively low recombination of photogenerated electron-hole pairs facilitated by the extraordinary electrical conductivity of the CNTs [30].

In this work, we attempt to incorporate CNTs with $\mathrm{TiO}_{2}$ photoanodes in order to achieve a more sensitive determination of organic compounds in comparison with the corresponding pure $\mathrm{TiO}_{2}$ photoanodes. Both the CNTs/TiO 2 and the pure $\mathrm{TiO}_{2}$ thin film photoanodes were constructed using a dip-coating technique. After a series of calcination processes, the resultant thin film photoanodes were characterized using a scanning electron microscope (SEM), $\mathrm{X}$-ray diffraction (XRD) and a UV-visible spectrophotometer (UV-vis). The hydrophilicity property was appraised by measuring their contact angles. In a photoelectrochemical bulk cell, the resultant $\mathrm{CNTs} / \mathrm{TiO}_{2}$ photoanodes and the pure $\mathrm{TiO}_{2}$ photoanodes were used to detect low adsorptive compounds with hydroxylic functional group [31, 32], i.e. glucose and phenol, and highly adsorptive compounds with carboxylic functional groups [33], i.e. potassium hydrogen phthalate (KHP). The sensing performances of the $\mathrm{CNTs} / \mathrm{TiO}_{2}$ photoanodes and the pure $\mathrm{TiO}_{2}$ photoanodes were evaluated and compared.

\section{Experimental details}

\subsection{Chemicals and materials}

Indium tin oxide (ITO) conductive glass slides ( $8 \Omega$ /square) were commercially supplied by Delta Technologies Limited. Titanium butoxide (97\%), potassium hydrogen phthalate, Dglucose, phenol, sodium nitrate, isopropyl alcohol, concentrated nitric acid and carbowax 20M (Supelco) were of analytical grade and used as supplied without purification. All the chemicals were purchased from Sigma-Aldrich unless otherwise stated. All the solutions were prepared using high purity deionized water (Millipore Corp., $18 \mathrm{M} \Omega \mathrm{cm}$ ). Multi-walled CNTs were purchased from Shenzhen NanoTechnologies Port Co. Ltd.

\subsection{Pre-treatment of CNTs}

The CNTs need to be treated with strong acid to avoid agglomeration. Typically, $0.6 \mathrm{~g}$ of CNTs was added into $80 \mathrm{ml}$ concentrated $\mathrm{HNO}_{3}-\mathrm{H}_{2} \mathrm{SO}_{4}(1: 3, \mathrm{v} / \mathrm{v})$ under constant stirring at $60{ }^{\circ} \mathrm{C}$ for $10 \mathrm{~h}$. The mixture was filtered and washed with Milli-Q water until the $\mathrm{pH}$ of the filtrate reached 6.0. The pretreated CNTs were dried at $65^{\circ} \mathrm{C}$ in an oven.

\subsection{Fabrication and characterization of the pure $\mathrm{TiO}_{2}$ and CNTs/TiO 2 photoanodes}

The $\mathrm{TiO}_{2}$ colloid was synthesized by the hydrolysis of titanium butoxide [34]. Briefly, $25 \mathrm{ml}$ titanium butoxide with $8 \mathrm{ml}$ isopropanol was added dropwise into $0.1 \mathrm{M}$ nitric acid solution under vigorous stirring at room temperature $\left(23^{\circ} \mathrm{C}\right)$. The slurry was kept in a water bath at $80^{\circ} \mathrm{C}$, stirred and peptized for $10 \mathrm{~h}$. The resultant colloid was hydrothermally treated at $200{ }^{\circ} \mathrm{C}$ for $12 \mathrm{~h}$. The solid concentration of $\mathrm{TiO}_{2}$ was adjusted to $6 \%(\mathrm{w} / \mathrm{w})$ with water. Carbowax $(1.8 \%, \mathrm{w} / \mathrm{w})$ was added as a binder into the resultant colloid. It is well recognized that the carbowax (polyethylene glycol) is able to improve the mechanical strength and increase the porosity and surface area, from our works and other main stream researches in these fields [35-37]. The pre-treated CNTs (5 wt\% with respect to Q.4 the mass of $\mathrm{TiO}_{2}$ ) were subsequently added into this colloid, and sonicated (Digital Sonifer, Branson) for $40 \mathrm{~min}$ to improve the interaction between the $\mathrm{TiO}_{2}$ colloid and CNTs. The ITO glass slides were washed with acetone and then Milli-Q water to assure the cleanliness. The $\mathrm{CNTs} / \mathrm{TiO}{ }_{2}$ colloid was dipcoated onto the ITO substrates, dried in ambient environment and annealed at $450{ }^{\circ} \mathrm{C}$ for $0.5 \mathrm{~h}$ in air. After cooling, the substrates were dip-coated again and annealed at $700^{\circ} \mathrm{C}$ for $2 \mathrm{~h}$ in $\mathrm{N}_{2}$ atmosphere. The pure $\mathrm{TiO}_{2}$ photoanodes (i.e., the control sample) were also prepared with CNTs-free $\mathrm{TiO}_{2}$ colloid using the same procedure. The variations of the film thicknesses of the nanomaterials of the $\mathrm{TiO}_{2}$ photoanode and $\mathrm{CNTs} / \mathrm{TiO}_{2}$ photoanode were $600 \mathrm{~nm} \pm 3 \%$ and $600 \mathrm{~nm} \pm$ $3.5 \%$, respectively. The difference of thickness is therefore negligible.

The surface morphology of the $\mathrm{CNTs} / \mathrm{TiO}_{2}$ photoanode was characterized by scanning electron microscopy (SEM, JSM 890). The crystalline phase of the thin film was determined by an x-ray diffractometer (Bruker) with $\mathrm{Cu}-\mathrm{K} \alpha$ radiation. Transmittance spectra were obtained using a UV1601 spectrophotometer (Shimazu, Japan). The hydrophilic property of the $\mathrm{CNTs} / \mathrm{TiO}_{2}$ thin film was evaluated by means of a commercial contact angle meter (FTA200 Dynamic Contact Angle Analyzer).

\subsection{Photoelectrocatalytic degradation of organic compounds}

A three-electrode photoelectrochemical system was used to investigate the photoelectrocatalytic oxidation of organic compounds at the $\mathrm{TiO}_{2}$ and $\mathrm{CNTs} / \mathrm{TiO}_{2}$ photoanodes [34]. The experiments were performed at room temperature $\left(23^{\circ} \mathrm{C}\right)$. A $\mathrm{TiO}_{2}$ or $\mathrm{CNTs} / \mathrm{TiO}_{2}$ thin film photoanode was used as the working electrode. The working electrode was fitted into an electrode holder with ca. $0.78 \mathrm{~cm}^{2}$ left unsealed to be exposed to the solution and for UV illumination. A saturated $\mathrm{Ag} / \mathrm{AgCl}$ electrode and a platinum mesh were used as the reference and auxiliary electrodes respectively. The supporting electrolyte was $0.1 \mathrm{M} \mathrm{NaNO}_{3}$. A voltammograph $(\mathrm{CV}-27, \mathrm{BAS})$ was 
used to measure the photocurrent under controlled potential and linear sweep voltammetry (LSV) experiments. Potential and current signals were recorded by a PC coupled with a Maclab 400 interface (AD Instruments). A $150 \mathrm{~W}$ xenon (HFC-150, TrustTech, Beijing, China) with regulated optical output and a UV-band-pass filter (UG-5, Schott) were placed in front of the quartz window to prevent the testing solution from being heated up. The light intensity at the working electrode surface was controlled at $6.6 \mathrm{~mW} \mathrm{~cm}{ }^{-2}$ in this work, measured at $365 \mathrm{~nm}$ wavelength using a UV irradiance meter (UV-A Instruments of Beijing Normal University).

\section{Results and discussion}

\subsection{Preparation and materials characterization of the CNTs/TiO 2 photoanode}

It is well established that the crystallinity of $\mathrm{TiO}_{2}$ plays an essential role in the photocatalytic activity. $\mathrm{TiO}_{2}$ with poor crystallinity, such as amorphous $\mathrm{TiO}_{2}$, normally has low photocatalytic activity due to the severe structural defects that often act as the recombination centers of photogenerated electrons and holes [38]. A simple calcination process at a high temperature (e.g., $450{ }^{\circ} \mathrm{C}$ ) is an effective way to improve the crystallinity of the $\mathrm{TiO}_{2}$ semiconductor [38]. In our previous study, we synthesized $\mathrm{TiO}_{2}$ colloid via a sol-gel process and fabricated $\mathrm{TiO}_{2}$ thin film using a dip-coating process. It was found that the $\mathrm{TiO}_{2}$ thin film consists of almost $100 \%$ anatase $\mathrm{TiO}_{2}$ after a calcination process at $450{ }^{\circ} \mathrm{C}$, while the thin film consists of mixed phases (i.e., anatase and rutile) when it is further treated at a temperature above $700^{\circ} \mathrm{C}$ in air [34]. Moreover, the mixed-phase $\mathrm{TiO}_{2}$ shows better photocatalytic degradation ability than pure phase $\mathrm{TiO}_{2}$ thin film [34].

In order to obtain the mixed-phase $\mathrm{TiO}_{2}$ compositions, the dip-coated $\mathrm{CNTs} / \mathrm{TiO}_{2}$ composite photoanodes were subjected to a calcination process at $700{ }^{\circ} \mathrm{C}$. The thermal stability of CNTs in air was first investigated. After the thermal treatment at $450{ }^{\circ} \mathrm{C}$ in air for $2 \mathrm{~h}$, it was observed that the overall tubular structure of the CNTs still remained intact (see figures 1(a) and (b)). A further thermal treatment at $700{ }^{\circ} \mathrm{C}$ in air resulted in a complete decomposition of the CNTs into $\mathrm{CO}_{2}$. This problem was overcome by protecting the photoanodes with high purity $\mathrm{N}_{2}$ in the calcination process. It was found that the appearance of the typical CNTs after being treated at $700{ }^{\circ} \mathrm{C}$ in $\mathrm{N}_{2}$ (see figure 1(c)) was identical to that of the untreated CNTs. According to these findings, the as-coated $\mathrm{CNTs} / \mathrm{TiO}_{2}$ photoanodes in this work were first calcined at $450{ }^{\circ} \mathrm{C}$ in air for $0.5 \mathrm{~h}$ in order to remove the carbowax (the binder), achieve strong bindings among the anatase $\mathrm{TiO}_{2}$ particles, CNTs and substrates without damage of CNTs, and improve the crystallinity. The photoanodes were then sintered at $700{ }^{\circ} \mathrm{C}$ for $2 \mathrm{~h}$ in the $\mathrm{N}_{2}$ atmosphere in an attempt to achieve the partial phase transition from anatase to rutile. The physical properties of $\mathrm{TiO}_{2}$ nanomaterials are influenced by the thermal treatment with different surrounding atmospheres [39]. The crystalline phases of the resultant photoanode from this calcination process (in the $\mathrm{N}_{2}$ atmosphere) which were not investigated previously [34] have been analyzed in this work.

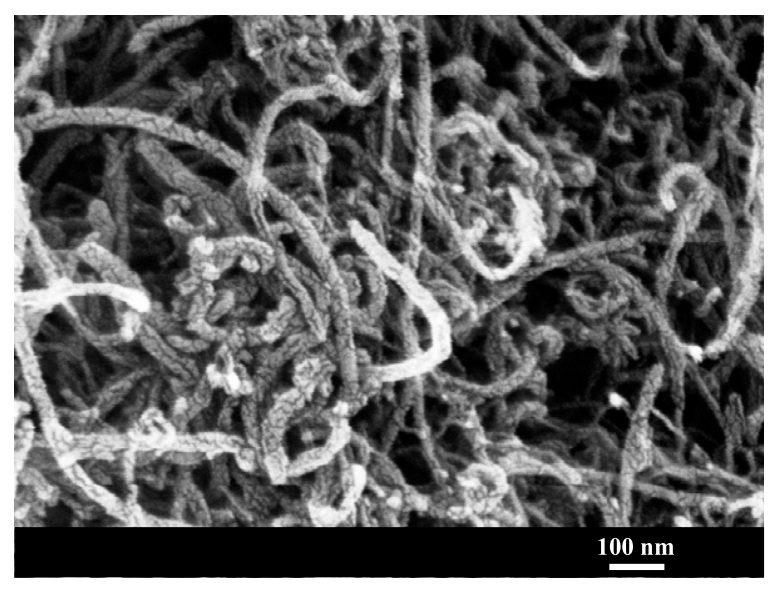

(a)

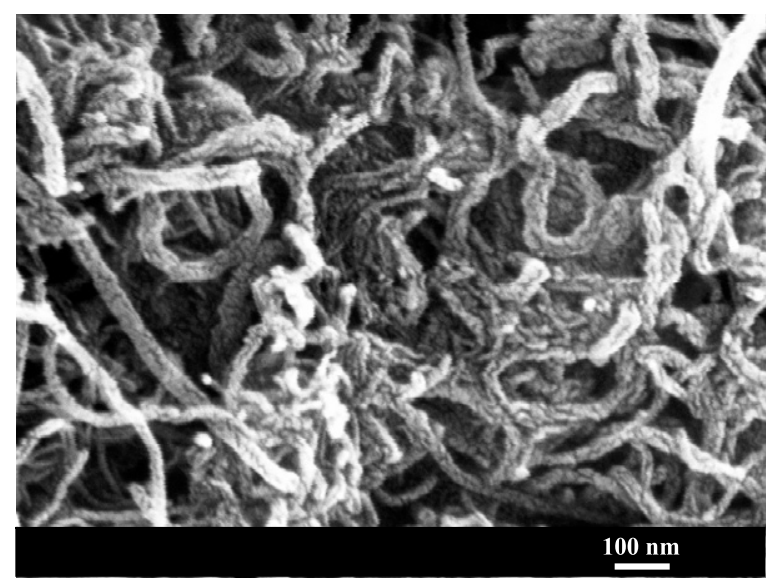

(b)

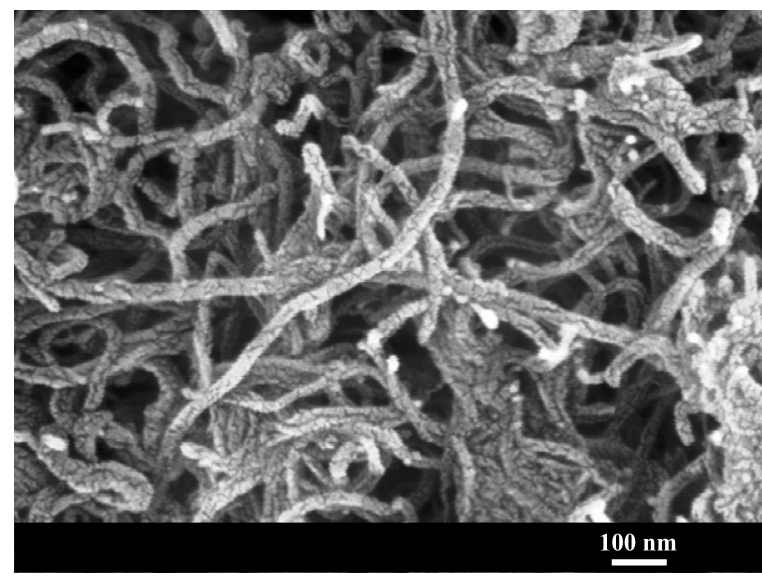

(c)

Figure 1. SEM images of CNTs under different thermal treatment conditions: (a) the original CNTs without thermal treatment; (b) the CNTs calcined at $450^{\circ} \mathrm{C}$ for $2 \mathrm{~h}$ in air; (c) the CNTs calcined at $700^{\circ} \mathrm{C}$ for $2 \mathrm{~h}$ in $\mathrm{N}_{2}$.

Figure 2 shows the XRD patterns of the pure $\mathrm{TiO}_{2}$ photoanode (curve (a)) and the $\mathrm{CNTs} / \mathrm{TiO}_{2}$ photoanode (curve (b)) after $700{ }^{\circ} \mathrm{C}$ calcination. It suggests that the introduction of CNTs had no significant effect on the crystallinity of $\mathrm{TiO}_{2}$. Both of the films consist of anatase and rutile, confirmed by characteristic diffraction peaks of anatase 


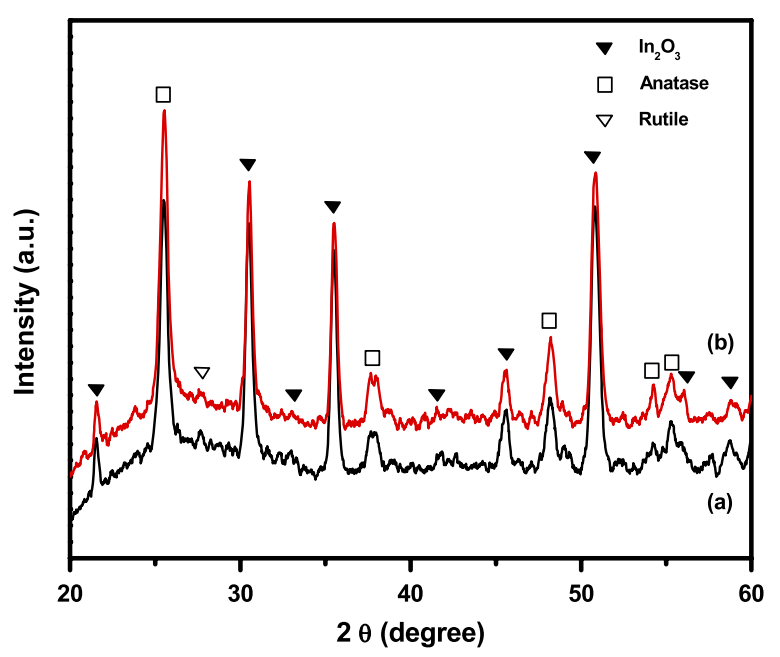

Figure 2. XRD patterns of the pure $\mathrm{TiO}_{2}$ (a) and $\mathrm{CNTs} / \mathrm{TiO}_{2}$ photoanodes (b), both of them were calcined at $450{ }^{\circ} \mathrm{C}$ in air and $700{ }^{\circ} \mathrm{C}$ in $\mathrm{N}_{2}$ protection atmosphere.

at $2 \theta$ degrees of 25.50 and rutile at $2 \theta$ degrees of 27.68. The $\mathrm{CNTs} / \mathrm{TiO}_{2}$ film contained $93 \%$ of anatase and $7 \%$ of rutile, while the pure $\mathrm{TiO}_{2}$ film had a similar ratio $(92 \%$ of anatase and $8 \%$ of rutile). The characteristic peak for CNTs at the position of 26.0 [40] was insignificant, which was consistent with the results in other literatures $[28,30]$. This may be attributed to the overlap of the intense peaks of the CNTs $\left(\begin{array}{lll}0 & 0 & 2\end{array}\right)$ at $2 \theta$ degrees of 26.0 and strong anatase $\left(\begin{array}{lll}0 & 0 & 1\end{array}\right)$ peak at $2 \theta$ degrees of 25.5 , as the mass of the CNT is only $5 \%$ of the mass of the $\mathrm{TiO}_{2}$ in the $\mathrm{CNTs} / \mathrm{TiO}_{2}$ film.

The surface morphology of the $\mathrm{CNTs} / \mathrm{TiO}_{2}$ film was examined by the SEM, which is shown in figure 3(a). The

Q.5 morphology of the $\mathrm{CNTs} / \mathrm{TiO}_{2}$ film and the within structure of the $\mathrm{CNTs} / \mathrm{TiO}_{2}$ are significantly different from results from Eder and Windle's group [41]. The difference is possibly due to dramatically different experimental conditions. In our work, we used hydrothermal processed highly crystalline $\mathrm{TiO}_{2}$ nanoparticles with various shape and sizes, different CNTs, different concentrations of CNTs, different CNT treatment methods, carbowax as a binder, and different calcination procedures. In our work, the average $\mathrm{TiO}_{2}$ particle size of the $\mathrm{CNTs} / \mathrm{TiO}_{2}$ sample is ca. $25-50 \mathrm{~nm}$, which is roughly the same as that of the pure $\mathrm{TiO}_{2}$ photoanode [34]. This suggests that the addition of the CNTs did not change the particle size and its distribution. It is generally difficult to observe the CNTs from the $\mathrm{CNTs} / \mathrm{TiO}_{2}$ photoanode surface possibly due to the facts that only a relatively small amount of CNTs (e.g., $5 \%$ of the $\mathrm{TiO}_{2}$ nanoparticles) are used, and the CNTs can be strongly incorporated with $\mathrm{TiO}_{2}$ due to the CNT surfaces being activated by the acid treatment. To observe the distribution of the CNTs, a cross-section sample was therefore prepared and observed under the SEM (see figure 3(b)). It reveals that the CNTs were evenly distributed and well cemented into the $\mathrm{TiO}_{2}$ film. This observation suggests that the physical structure of the CNTs was well maintained through this $700{ }^{\circ} \mathrm{C}$ calcination process and the protection by the $\mathrm{N}_{2}$ atmosphere was effective. This was consistent with the observation from figure 1 . From the above analyses, we can safely conclude that

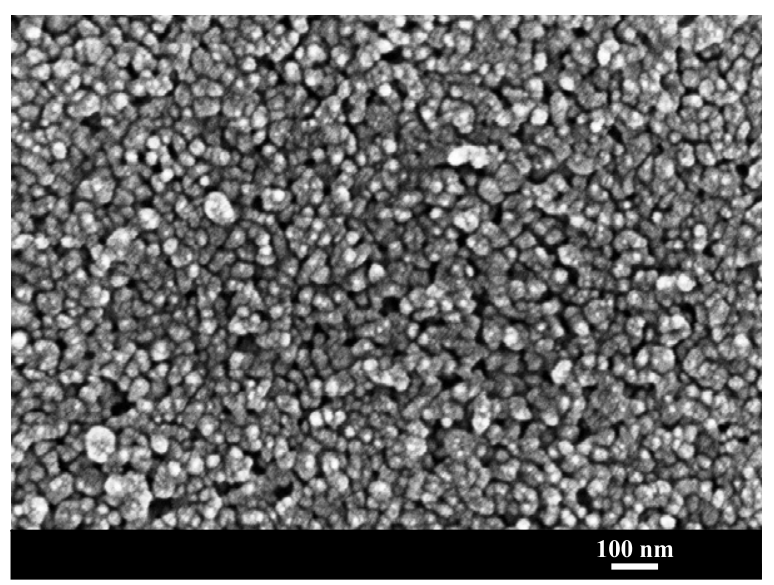

(a)

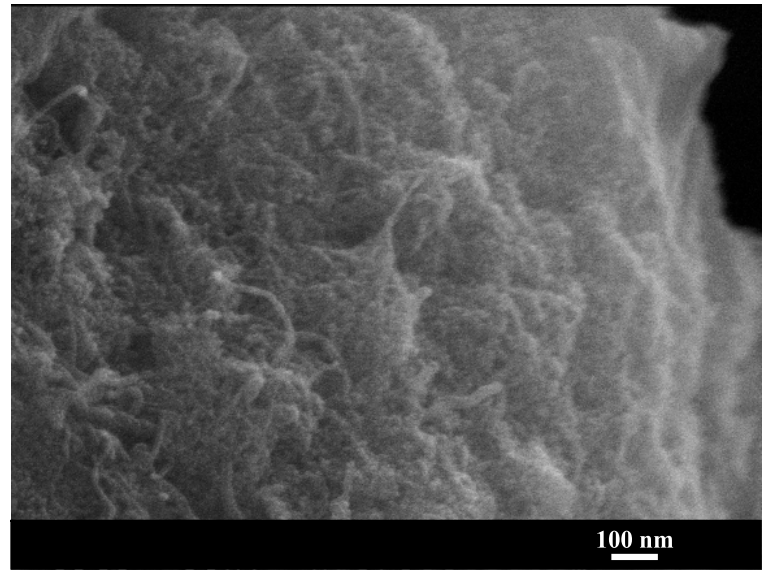

(b)

Figure 3. Top-viewed (a) and cross-sectional (b) SEM images of the $\mathrm{CNTs} / \mathrm{TiO}_{2}$ photoanode after the calcination processes at $450{ }^{\circ} \mathrm{C}$ in air and $700{ }^{\circ} \mathrm{C}$ in $\mathrm{N}_{2}$ protection atmosphere.

the $\mathrm{CNTs} / \mathrm{TiO}_{2}$ mixed-phase photoanode and the pure $\mathrm{TiO}_{2}$ mixed-phase photoanode can be obtained via the calcination process at $700^{\circ} \mathrm{C}$ in $\mathrm{N}_{2}$ protection atmosphere.

The UV-vis transmittance spectra of the ITO glass (curve (a)), the pure $\mathrm{TiO}_{2}$ (curve (b)) and $\mathrm{CNTs} / \mathrm{TiO}_{2}$ photoanodes (curve (c)) are presented in figure 4. Curve (a) indicates that the aluminosilicate ITO glass has no absorption in the visible light and near UV region. Curve (b) shows that the band edge absorption of the $\mathrm{TiO}_{2}$ was at ca. $390 \mathrm{~nm}$, typical for anatase. Compared with curve (b), the absorption edge of curve (c) was shifted into the visible light region significantly due to the introduction of CNTs. Because pure CNTs have significant absorbance over the entire visible light region [42], wide optical absorptions in the visible light region are also observed for the $\mathrm{CNTs} / \mathrm{TiO}_{2}$ photoanode.

Besides the absorption, the surface properties such as hydrophilicity of the $\mathrm{TiO}_{2}$ surface could be affected by the introduction of the CNTs as well. The change of the hydrophilicity can be reflected by the variation of the contact angle with pure water. The measured contact angles were $60.2^{\circ}$ and $36.3^{\circ}$ on the pure $\mathrm{TiO}_{2}$ film and the $\mathrm{CNTs} / \mathrm{TiO}_{2}$ film respectively, indicating a significant increase in hydrophilicity 


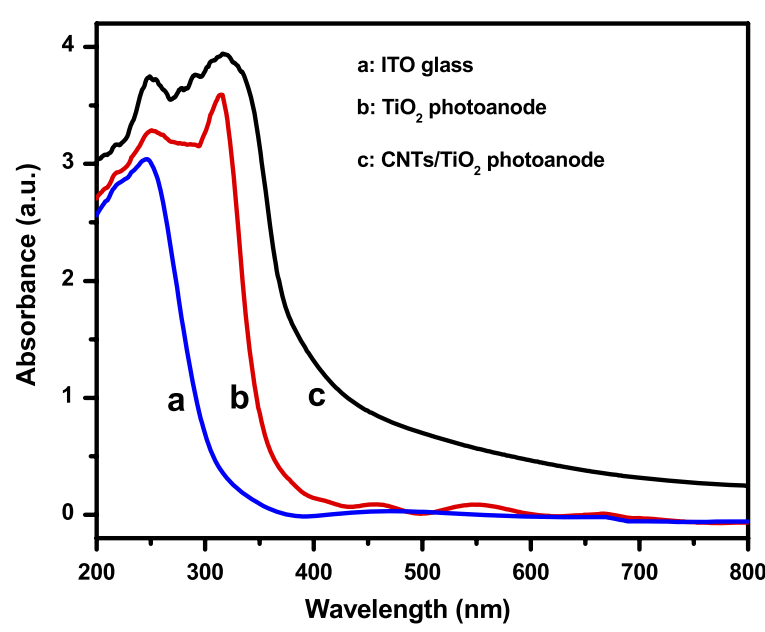

Figure 4. UV-vis absorption spectra of ITO glass substrate (a), pure $\mathrm{TiO}_{2}$ photoanode (b) and CNTs/TiO 2 photoanode (c).

by the introduction of the CNTs. This is probably due to several reasons. Firstly, the acid pre-treatment which involves the oxidation of the CNTs and formation of hydrophilic functional groups (e.g. hydroxyl, carboxyl, and carbonyl) on the CNTs' surface [43]. Secondly, the $\mathrm{TiO}_{2}$ film is porous due to the use of carbowax. Thirdly, the $\mathrm{TiO}_{2}$ and $\mathrm{CNTs} / \mathrm{TiO}_{2}$ film are very thin (i.e., only $600 \mathrm{~nm}$ ). When the water solution is applied on the surface of the photoanodes, water molecules are able to reach the internal structure, i.e., the hydrophilic CNTs' surface, leading to the increase of the surface hydrophilicity. The hydrophilic surface favors the adsorption of hydrophilic organic compounds, which may benefit the adsorption process of the organic compounds during the photocatalytic oxidation at the $\mathrm{CNTs} / \mathrm{TiO}_{2}$ photoanode.

\subsection{Photoelectrochemical oxidation of water}

The photoelectrocatalytic oxidation of water was first investigated since the response of the photocurrent resulting from the oxidation or reduction of water may influence the electrochemical measurements in aqueous solutions. Figure 5 shows the voltammograms recorded at the pure $\mathrm{TiO}_{2}$ and $\mathrm{CNTs} / \mathrm{TiO}_{2}$ photoanodes in $0.1 \mathrm{M} \mathrm{NaNO}_{3}$ (as electrolyte) under the same UV illumination intensity. It can be seen that for both photoanodes, the photocurrent increased with the applied potential bias at low potential range $(-0.4$ to $+0.2 \mathrm{~V}$ ) then leveled off at more positive potentials (greater than $+0.2 \mathrm{~V}$ ). The initial increase in the photocurrents was because the overall reactions at both photoanodes were under the control of the electron transfer process. The increased potential will produce increased electric field to draw electrons from the photoanode surface to the conductive back contact. The photocurrent leveling off at higher potentials (greater than $+0.2 \mathrm{~V}$ ) was due to the transportation of electroactive substance (i.e., $\mathrm{H}_{2} \mathrm{O}$ ) from the bulk to the photoanode surface becoming the limiting step. It was found that the potential $+0.3 \mathrm{~V}$ was able to provide sufficient electric field to collect electrons generated from the catalytic reactions at the surface. Therefore, the collection of the electrons will no longer be the

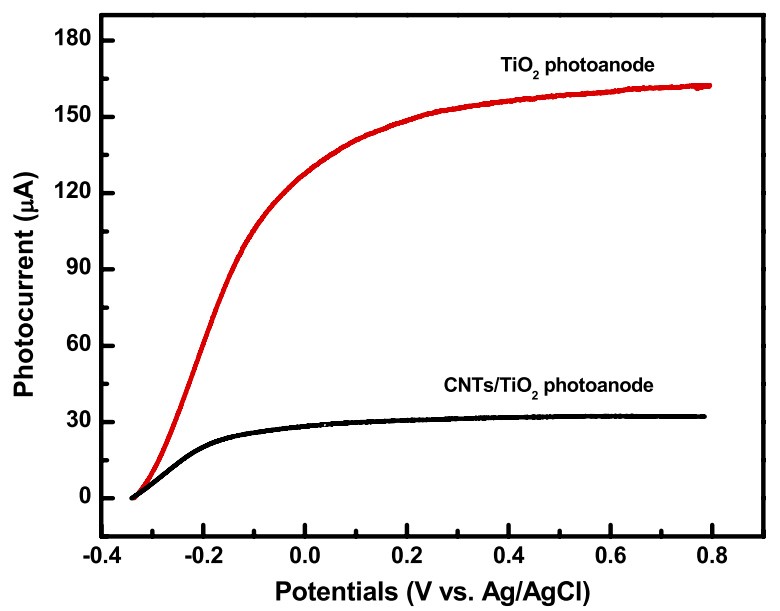

Figure 5. Voltammograms of the pure $\mathrm{TiO}_{2}$ photoanode and $\mathrm{CNTs} / \mathrm{TiO}_{2}$ photoanode in $0.1 \mathrm{M} \mathrm{NaNO}_{3}$ electrolyte under UV illumination.

limiting step and the further increase of potential will not lead to significant increase of the photocurrent. In this scenario, the magnitude of the photocurrent can be used to represent the photocatalytic activity of the photoanode. As shown in figure 5 under the same potential bias and experimental conditions, the photocurrent of the $\mathrm{CNTs} / \mathrm{TiO}_{2}$ photoanode was about $20 \%$ of the photocurrent of the pure $\mathrm{TiO}_{2}$ photoanode, suggesting that the photocatalytic oxidation of water at the photoanode had been reduced by $80 \%$ due to the introduction of the CNTs compared with the pure $\mathrm{TiO}_{2}$ photoanode. From the viewpoint of analytical chemistry, the water oxidation current is commonly considered as the background current. Therefore, the characteristic of low background current will be an advantage of the $\mathrm{CNTs} / \mathrm{TiO}_{2}$ photoanode over the pure $\mathrm{TiO}_{2}$ current.

\subsection{Photoelectrocatalytic oxidation of organic compounds}

The general electrochemical equation for complete mineralization of an organic compound, $\mathrm{C}_{y} \mathrm{H}_{m} \mathrm{O}_{j} \mathrm{~N}_{k} \mathrm{X}_{q}$, on a $\mathrm{TiO}_{2}$ electrode can be represented as in equation (1) [44]:

$$
\begin{aligned}
\mathrm{C}_{y} \mathrm{H}_{m} \mathrm{O}_{j} \mathrm{~N}_{k} \mathrm{X}_{q}+(2 y-j) \mathrm{H}_{2} \mathrm{O} \rightarrow \\
\quad y \mathrm{CO}_{2}+q \mathrm{X}^{-}+k \mathrm{NH}_{3}+(4 y-2 j+m-3 k) \mathrm{H}^{+} \\
\quad+(4 y-2 j+m-3 k-q) \mathrm{e}^{-}
\end{aligned}
$$

where $\mathrm{X}$ represents a halogen atom. The electron transfer number $(n)$ in the complete mineralization of the organic compound is equal to $4 y-2 j+m-3 k-q$.

Glucose, phenol and KHP were selected to study the photoelectrochemical performance of the $\mathrm{CNTs} / \mathrm{TiO}_{2}$ and $\mathrm{TiO}_{2}$ photoanodes. Because it can be seen from section 3.2 that the mass transport of electroactive substance (i.e. $\mathrm{H}_{2} \mathrm{O}$ ) from the bulk to the photoanode surface became the limiting step when the potential bias was higher than $+0.2 \mathrm{~V}$ (see figure 5), a potential bias of $+0.3 \mathrm{~V}$ was chosen for subsequent photoelectrocatalytic experiments to obtain a steady state current. At this potential, the recombination of photoinduced electron-hole pairs was sufficiently suppressed. Two sets 

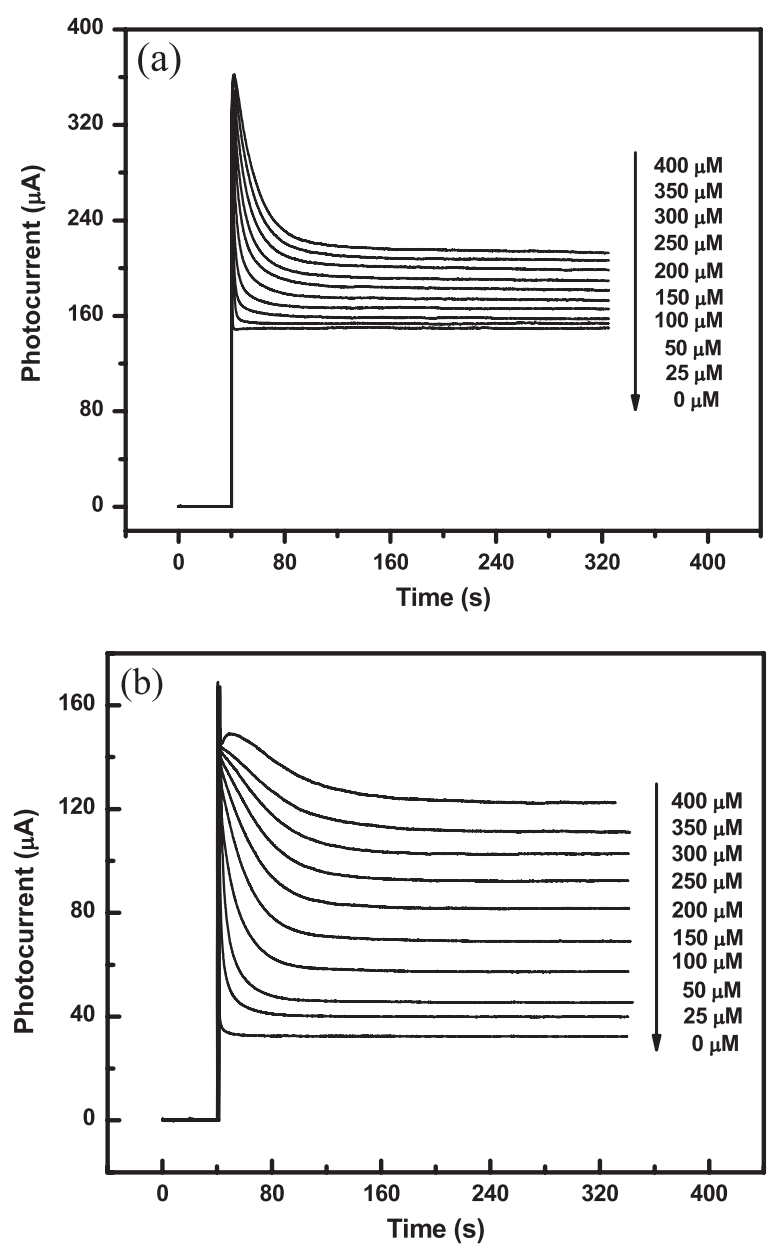

Figure 6. Typical photocurrent responses of the pure $\mathrm{TiO}_{2}$ photoanode (a) and the $\mathrm{CNTs} / \mathrm{TiO}_{2}$ photoanode (b) to different concentrations of glucose.

of photocurrent-time profiles of the pure $\mathrm{TiO}_{2}$ photoanode (see figure 6(a)) and $\mathrm{CNTs} / \mathrm{TiO}_{2}$ photoanode (see figure 6(b)) were obtained from solutions containing $0.1 \mathrm{M} \mathrm{NaNO}_{3}$ and different concentrations of glucose under the UV illumination, respectively. For the blank solution $\left(0.1 \mathrm{M} \mathrm{NaNO}_{3}\right)$, where the glucose concentration was zero, the photocurrent went up quickly and then leveled off and eventually a steady state current was obtained, named as $i_{\text {blank }}$. For all glucose concentrations in figures $6(\mathrm{a})$ and (b), the photocurrents increased rapidly to a peak value and decayed to the steady state, which was nominated as $i_{\text {total }}$. Moreover, an abrupt spike in the photocurrent (in a time domain of $1 \mathrm{~s}$ ) was observed for the $\mathrm{CNTs} / \mathrm{TiO}_{2}$ photoanode but not for the pure $\mathrm{TiO}_{2}$ one. This spike may result from the pre-adsorbed water and glucose at the $\mathrm{CNTs} / \mathrm{TiO}_{2}$ photoanode. This preadsorption phenomenon was much less significant at the pure $\mathrm{TiO}_{2}$ photoanode. This difference implies that the adsorptive property of the $\mathrm{CNTs} / \mathrm{TiO}_{2}$ photoanode to water and glucose is stronger than that of the pure $\mathrm{TiO}_{2}$ photoanode. This might be related to the aforementioned difference of the surface hydrophilicity.

It is well established that the steady state photocurrent for the blank solution $\left(i_{\text {blank }}\right)$ originated from the photo- electrocatalytic oxidation of water, while the steady state photocurrent for the glucose solutions $\left(i_{\text {total }}\right)$ was generated from the oxidation of water and glucose [44]. A net steady state photocurrent $\left(i_{\text {net }}\right)$, originated from the oxidation of glucose, can be obtained by subtracting $i_{\text {blank }}$ from $i_{\text {total }}$ as in equation (2). $i_{\text {net }}$ can be used to represent the oxidation rate of the corresponding organic compound and also quantify the concentration of organic compounds in aqueous samples [44]. Therefore, higher net current when oxidizing organic compounds suggests a faster oxidation rate of the organic compounds in terms of oxidation kinetics and higher sensitivity in terms of analytical performance:

$$
i_{\text {net }}=i_{\text {total }}-i_{\text {blank }} \text {. }
$$

Using equation (2), the $i_{\text {net }}$ values of different photoanodes can be obtained from figures 6(a) and (b) and plotted against the glucose concentration as shown in figure 7(a). Good linear relationships between the glucose concentration and $i_{\text {net }}$ were obtained from both photoanodes, indicating the both photoanodes are promising in the sensing application. The slope of the $i_{\text {net }}$-[glucose] calibration curve indicates the photoelectrocatalytic activity towards glucose oxidation. It is notable that the obtained slope value of the $\mathrm{CNTs} / \mathrm{TiO}_{2}$ photoanode is larger than that of the pure $\mathrm{TiO}_{2}$ photoanode, demonstrating that the photoelectrocatalytic activity of the $\mathrm{CNTs} / \mathrm{TiO}_{2}$ photoanode towards glucose oxidation was better than that of the pure $\mathrm{TiO}_{2}$ photoanode.

Similarly, the CNTs/TiO 2 photoanode and the pure $\mathrm{TiO}_{2}$ photoanode were used to detect phenol and KHP in $0.1 \mathrm{M}$ $\mathrm{NaNO}_{3}$ aqueous solution. The obtained $i_{\text {net }}$ values were plotted against [phenol] and [KHP] as shown in figures 7(b) and (c), respectively. At both the $\mathrm{CNTs} / \mathrm{TiO}_{2}$ and pure $\mathrm{TiO}_{2}$ photoanodes, good linear relationships were also observed for both phenol and KHP. More importantly, the slope values obtained from the $\mathrm{CNTs} / \mathrm{TiO}_{2}$ photoanode were larger than those from the pure $\mathrm{TiO}_{2}$ photoanode. This suggests that the $\mathrm{CNTs} / \mathrm{TiO}_{2}$ photoanode possesses better photocatalytic activity towards phenol and KHP oxidation than the pure $\mathrm{TiO}_{2}$ photoanode.

Interesting results were obtained when the $i_{\text {net }}$ in figure 7 were plotted against the equivalent concentrations $\left(C_{\text {eq }}\right)$ of all the organic compounds investigated. The equivalent concentration can be obtained by multiplying the electron transfer number $(n)$ with the corresponding molar concentration $\left(C_{\mathrm{M}}\right), C_{\mathrm{eq}}=n C_{\mathrm{M}}$ [34]. According to equation (1), the $n$ values of phthalic acid (i.e. KHP), phenol and glucose are 30, 28 and 24, respectively. Excellent linear relationships between $i_{\text {net }}$ and $C_{\text {eq }}$ were obtained at both the pure $\mathrm{TiO}_{2}$ and $\mathrm{CNTs} / \mathrm{TiO}_{2}$ photoanodes (see figures 8(a) and (b)). This is because the photocurrents were under the diffusion control of the organic compounds from the bulk solution to the photoanode surface. It is also remarkable that the slope of the $\mathrm{CNTs} / \mathrm{TiO}_{2}$ photoanode (i.e., 0.0102) was much larger than that of the pure $\mathrm{TiO}_{2}$ photoanode $(0.00621)$. In order words, the sensitivity of the $\mathrm{CNTs} / \mathrm{TiO}_{2}$ photoanode for the detection of the organic compounds has been improved by $64 \%$ in comparison with the pure $\mathrm{TiO}_{2}$ photoanode. This is 

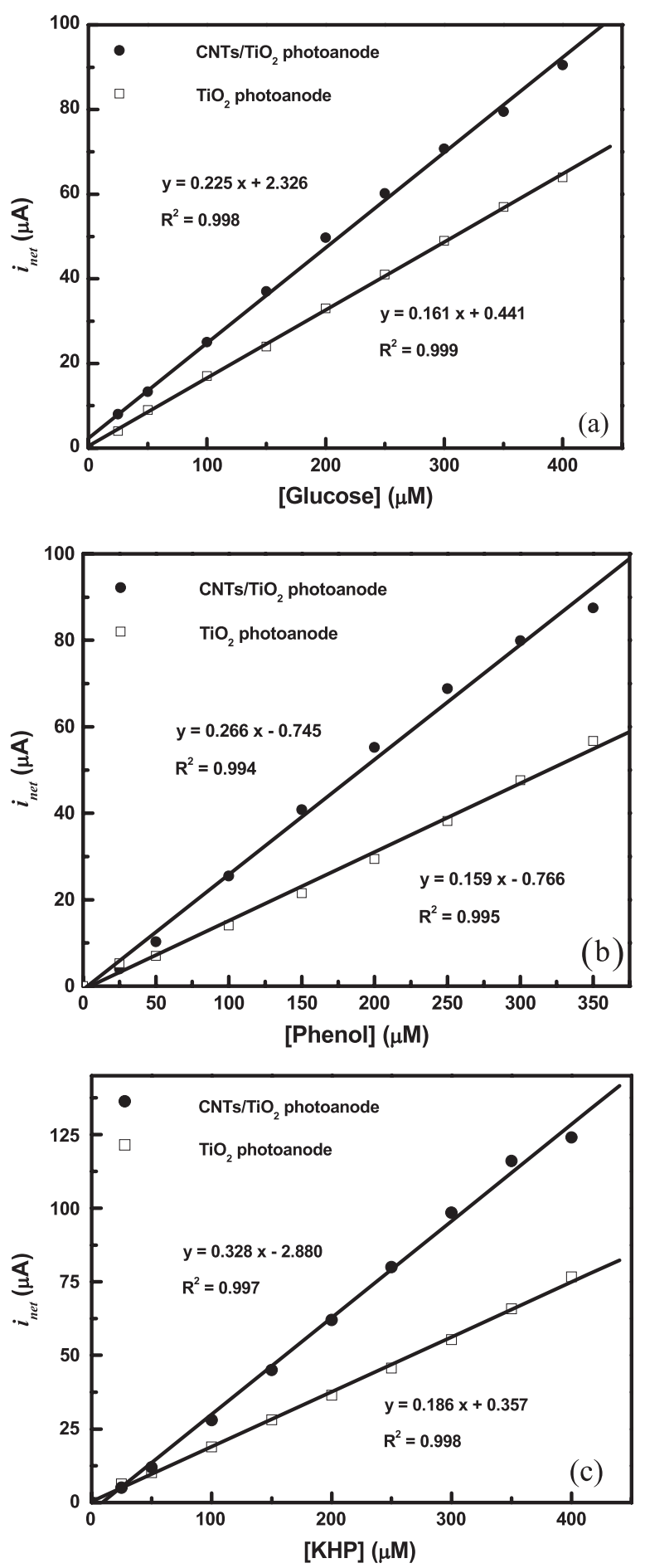

Figure 7. Plots of net photocurrent $i_{\text {net }}$ against glucose (a), phenol (b) and KHP (c) for the pure $\mathrm{TiO}_{2}$ and $\mathrm{CNTs} / \mathrm{TiO}_{2}$ photoanodes, respectively.

due to the $700^{\circ} \mathrm{C}$ thermal treatment process in $\mathrm{N}_{2}$ atmosphere and/or the introduction of CNTs.

According to the XRD spectra we obtained, the crystalline compositions (i.e., anatase and rutile ratio) of the $\mathrm{TiO}_{2}$ photoanode and $\mathrm{CNTs} / \mathrm{TiO}_{2}$ photoanode are very similar. In other words, the presence of the CNTs did not affect the rutile formation process in our work, which differs from
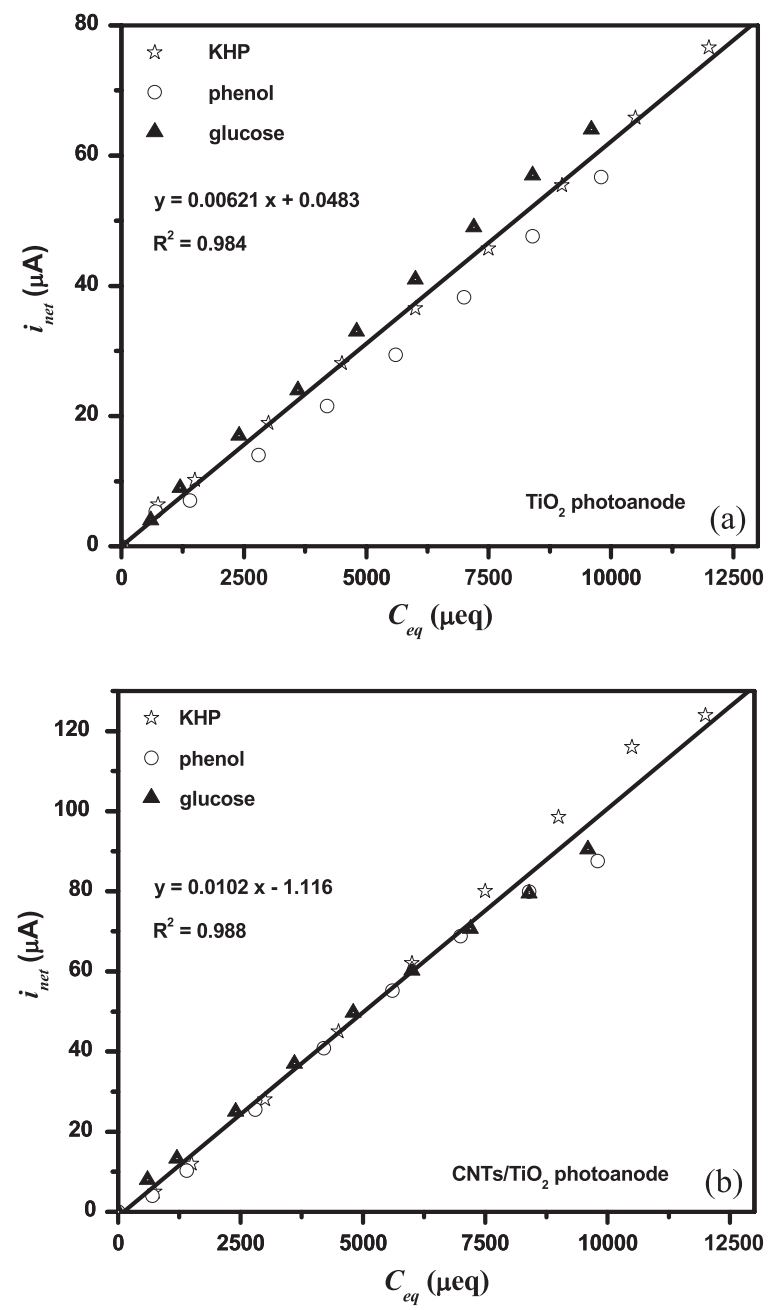

Figure 8. Relationship between $i_{\text {net }}$ and $C_{\text {eq }}$ at the pure $\mathrm{TiO}_{2}$ (a) and $\mathrm{CNTs} / \mathrm{TiO}_{2}$ (b) photoanodes, where $C_{\mathrm{eq}}(\mu \mathrm{eq})=n C_{\mathrm{M}}(\mu \mathrm{M})$.

a report in the literature [45]. This is probably due to numerous reasons: the use of carbowax binder, different CNTs, different shape (particles versus $\mathrm{TiO}_{2}$ nanotubes in the literature) and different CNT treatment method, and relatively shorter treatment time in our application ( $2 \mathrm{~h}$ compared with $4 \mathrm{~h}$ in the literature). Also the doped nitrogen in the $\mathrm{TiO}_{2}$ was not observed for both the $\mathrm{TiO}_{2}$ and $\mathrm{CNTs} / \mathrm{TiO}_{2}$ photoanodes according to their x-ray photoelectron spectroscopy (XPS) spectra (see figure S2 available at stacks.iop.org/Nano/21/ 000000/mmedia). Furthermore, the photocurrent was not obtained for both the $\mathrm{TiO}_{2}$ and $\mathrm{CNTs} / \mathrm{TiO}_{2}$ photoanodes under visible light. All of these eliminate the doping of nitrogen into the $\mathrm{TiO}_{2}$ lattice in our case. It can be concluded that the doping of $\mathrm{N}$ in the presence of the CNTs should not be responsible for the significant increase of the sensitivity of the $\mathrm{CNTs} / \mathrm{TiO}_{2}$ photoanode in this work.

The increase of sensitivity of the $\mathrm{CNTs} / \mathrm{TiO} 2$ photoanode, therefore, should result from the improved conductivity for electrons, i.e., enhanced electron transport or electron collection efficiency due to the extraordinary conductivity of the CNTs [46]. The CNTs interlinked with the $\mathrm{TiO}_{2}$ nanoparticles can act as 'electron transport superhighways'; 
therefore, the CNTs are able to facilitate the transport of the photogenerated electrons to the conducting substrate, and subsequently improve the electron collection efficiency and electron-hole separation percentage. This argument can be supported by the results from electrochemical impedance spectroscopy (EIS) measurement under UV illumination (see figure S1 available at stacks.iop.org/Nano/21/000000/ mmedia). It is well established that EIS is very effective for investigation of the properties of the electron transfer process across the $\mathrm{TiO}_{2}$-electrolyte interfaces under light [47]. The smaller impedance arc radius in Nyquist plots indicates faster electron transfer. As shown in figure S1 (available at stacks.iop.org/Nano/21/000000/mmedia), the impedances of the $\mathrm{TiO}_{2}$ and the $\mathrm{CNTs} / \mathrm{TiO}_{2}$ film are measured as around $1062 \Omega$ and $556 \Omega$, respectively. In other words, the electron transport ability of the $\mathrm{CNTs} / \mathrm{TiO}_{2}$ photoanode is better than that of the pure $\mathrm{TiO}_{2}$ photoanode.

Thus, it can be concluded that at a given concentration of a given organic compound, more sensitive response in $i_{\text {net }}$ can be obtained at the $\mathrm{CNTs} / \mathrm{TiO}_{2}$ photoanode than the pure $\mathrm{TiO}_{2}$ photoanode. This could be mainly due to the introduction of CNTs, which leads to the improved adsorptivity to organic compounds, increased absorption of UV light and improved electron transport and collection efficiency. For analytical chemistry, the incorporation of the CNTs into the $\mathrm{TiO}_{2}$ has led to a larger detection current and higher sensitivity.

\section{Conclusions}

CNTs/TiO 2 photoanodes and pure $\mathrm{TiO}_{2}$ photoanodes (as the control) were prepared, characterized and used for the detection of organic compounds. The CNTs have been successfully incorporated into the $\mathrm{TiO}_{2}$ nanostructure in the fabrication process of $\mathrm{CNTs} / \mathrm{TiO}_{2}$ photoanodes. The $\mathrm{TiO}_{2}$ particles on the resultant photoanodes have anatase and rutile mixed phases. The introduction of the CNTs into the $\mathrm{TiO}_{2}$ has increased the absorption of UV light, enhanced the hydrophilicity of the $\mathrm{TiO}_{2}$ surface and improved the electron collection efficiency. When the $\mathrm{CNTs} / \mathrm{TiO}_{2}$ photoanode was used in detecting organic compounds, the net photocurrents were directly proportional to the concentration of organics. In comparison with the pure $\mathrm{TiO}_{2}$ photoanodes, the $\mathrm{CNTs} / \mathrm{TiO}_{2}$ photoanodes have the advantages of high sensitivity and low background current in the determination of organic compounds in aqueous solutions.

\section{Acknowledgments}

The Authors acknowledge the financial support of the ARC discovery and ARC linkage grant from Australian Research Council.

\section{Q.7 References}

[1] Carp O, Huisman C L and Reller A 2004 Prog. Solid State Chem. 32 33-177

[2] Abrams B L and Wilcoxon J P 2005 Crit. Rev. Solid State Mater. Sci. 30 153-82
[3] Fujishima A, Zhang X and Tryk D A 2007 Int. J. Hydrog. Energy 32 2664-72

[4] Hashimoto K, Irie H and Fujishima A 2005 Japan. J. Appl. Phys. 44 8269-85

[5] Chen X and Mao S S 2007 Chem. Rev. 107 2891-959

[6] Hu X, Li G and Yu J C 2009 Langmuir 26 3031-9

[7] Chen Q, Xu D, Wu Z and Liu Z 2008 Nanotechnology 19365708

[8] Lu H F, Li F, Liu G, Chen Z G, Wang D W, Fang H T, Lu G Q, Jiang Z H and Cheng H M 2008 Nanotechnology 19405504

[9] Birkefeld L D, Azad A M and Akbar S A 1992 J. Am. Ceram. Soc. $752964-8$

[10] Sun L, Huo L, Zhao H, Gao S and Zhao J 2006 Sensors Actuators B 114 387-91

[11] Manera M G, Davide Cozzoli P, Leo G, Lucia Curri M, Agostiano A, Vasanelli L and Rella R 2007 Sensors Actuators B 126 562-72

[12] Zhang Y, Fu W, Yang H, Qi Q, Zeng Y, Zhang T, Ge R and Zou G 2008 Appl. Surf. Sci. 254 5545-7

[13] Xu Z and Yu J 2010 Nanotechnology 21245501

[14] Eder D 2010 Chem. Rev. 110 1348-85

[15] Moriguchi I, Hidaka R, Yamada H, Kudo T, Murakami H and Nakashima N 2006 Adv. Mater. 18 69-73

[16] Frank O, Kalbac M, Kavan L, Zukalova M, Prochazka J, Klementova M and Dunsch L 2007 Phys. Status Solidi b 244 4040-5

[17] Reddy A L M and Ramaprabhu S 2007 J. Phys. Chem. C $1117727-34$

[18] Kongkanand A, Martinez Dominguez R and Kamat P V 2007 Nano Lett. 7 676-80

[19] Song H, Qiu X and Li F 2008 Electrochim. Acta 53 3708-13

[20] Song H, Qiu X, Li F, Zhu W and Chen L 2007 Electrochem. Commun. 9 1416-21

[21] Yao Y, Li G, Ciston S, Lueptow R M and Gray K A 2008 Environ. Sci. Technol. 42 4952-7

[22] Bouazza N, Ouzzine M, Lillo-Ródenas M A, Eder D and Linares-Solano A 2009 Appl. Catal. B 92 377-83

[23] Jiang L-C and Zhang W-D 2009 Electroanalysis 21 988-93

[24] Llobet E et al 2008 Nanotechnology 19375501

[25] Sánchez M and Rincón M E 2009 Sensors Actuators B $14017-23$

[26] Shen Q, You S-K, Park S-G, Jiang H, Guo D, Chen B and Wang X 2008 Electroanalysis 20 2526-30

[27] Ueda T, Takahashi K, Mitsugi F and Ikegami T 2009 Diamond Relat. Mater. 18 493-6

[28] Gao B, Chen G Z and Li Puma G 2009 Appl. Catal. B 89 503-9

[29] Woan K, Pyrgiotakis G and Sigmund W 2009 Adv. Mater. $212233-9$

[30] Yu Y, Yu J C, Yu J-G, Kwok Y-C, Che Y-K, Zhao J-C, Ding L, Ge W-K and Wong P-K 2005 Appl. Catal. A 289 186-96

[31] Mills G and Hoffman M R 1993 Environ. Sci. Technol. 27 1681-9

[32] Solarska R, Rutkowskal I, Morand R and Augustynski J 2006 Electrochim. Acta $\mathbf{5 1} 2230-6$

[33] Chen J, Ollis D F, Rulkens W H and Bruning H 1999 Water Res. 33 669-76

[34] Jiang D L, Zhang S Q and Zhao H J 2007 Environ. Sci. Technol. 41 303-8

[35] Benkstein K D, Kopidakis N, van de Lagemaat J and Frank A J 2003 J. Phys. Chem. B 107 7759-67

[36] Kalyanasundaram K and Grätzel M 1998 Coord. Chem. Rev. $177347-414$ 
[37] Saito Y, Kambe S, Kitamura T, Wada Y and Yanagida S 2004 Sol. Energy Mater. Sol. Cells 83 1-13

[38] Zhang Q, Gao L and Guo J 2000 Appl. Catal. B 26 207-15

[39] Zhang H, Xie C, Zhang Y, Liu G, Li Z, Liu C, Ma X and Zhang W F 2008 J. Appl. Phys. 103103107

[40] An G, Ma W, Sun Z, Liu Z, Han B, Miao S, Miao Z and Ding K 2007 Carbon 45 1795-801

[41] Eder D and Windle A H 2008 J. Mater. Chem. 18 2036-43

[42] Xie Y, Heo S, Yoo S, Ali G and Cho S 2010 Nanoscale Res. Lett. 5 603-7
[43] Yan X-b, Tay B K and Yang Y 2006 J. Phys. Chem. B 110 25844-9

[44] Zhang S, Li L and Zhao H 2009 Environ. Sci. Technol. $437810-5$

[45] Eder D, Kinloch I A and Windle A H 2006 Chem. Commun. 1448-50

[46] Raffaelle R P, Landi B J, Harris J D, Bailey S G and Hepp A F 2005 Mater. Sci. Eng. B $116233-43$

[47] Yu H, Quan X, Chen S, Zhao H and Zhang Y 2008 J. Photochem. Photobiol. A 200 301-6 


\title{
Queries for IOP paper 362824
}

\author{
Journal: Nano \\ Author: $\quad$ L Li et al \\ Short title: Fabrication of $\mathrm{CNTs} / \mathrm{TiO}_{2}$ photoanodes for \\ sensitive determination of organic compounds
}

\section{Page 1}

Query 1:

Author: Please check the author names and affiliations carefully.

Query 2:

Author: 'In comparison with the pure $\mathrm{TiO}_{2}$ photoanode' was repeated in this sentence. The apparent duplication has been removed. Please check the edited version, and correct if necessary.

Query 3:

Author: Please be aware that the colour figures in this article will only appear in colour in the Web version. If you require colour in the printed journal and have not previously arranged it, please contact the Production Editor now.

\section{Page 2}

Query 4:

Author: Please check the edits made in the sentence 'It is well recognized that the carbowax..., and correct if necessary.

\section{Page 4}

Query A:

Author: Do you mean 'protective atmosphere' here and in two other places?

Query 5:

Author: Please clarify 'within structure'. Do you mean 'internal structure'?

\section{Page 8}

Query 6:

Author: Please check/confirm 'organic compound' here. Please check.

Query 7:-

Author: Please check the details for any journal references that do not have a blue link as they may contain some incorrect information. Pale purple links are used for references to arXiv e-prints. 